\title{
A case study on separation of IPA-water mixture by extractive distillation using aspen plus
}

\author{
Sarita Kalla, Sushant Upadhyaya*, Kailash Singh, Rajeev Kumar Dohare and Madhu Agarwal \\ Department of Chemical Engineering, Malaviya National Institute of Technology, Jaipur, India
}

\section{(C)2016 ACCENTS}

\begin{abstract}
Extractive distillation is one of the popular methods being leveraged to separate isopropyl alcohol (IPA) from water present in waste stream in semi-conductor industries. In this context, the paper aims to carry out simulation study for separation of isopropyl alcohol-water azeotrope mixture using ethylene glycol as entrainer. In particular, temperature, pressure and concentration profile has been studied. Aspen plus ${ }^{\circledR}$ (version 8.8) has been used as simulation tool and optimum number of stages for the simulation turns out to be 42. The results show that top of the column contains IPA of $99.974 \mathrm{~mol} \%$ purity and bottom product contains water-ethylene glycol mixture. Moreover, sensitivity analysis for different parameters and analysis of residue curve for ternary system have been also performed.
\end{abstract}

\section{Keywords}

IPA-water. Extractive distillation. Simulation. Entrainer.

\section{Introduction}

Isopropyl alcohol is generally used as the cleaning agent and solvent in chemical industries. Because of its cleaning property it is also known as rubbing alcohol. IPA is soluble in water and it forms azeotrope with water at temperature 80.3-80.4 0C. IPA and water forms a homogeneous minimum boiling azeotrope, at 68.1-67.5 mole\% (87.4-87.7 mass \%) under atmospheric conditions [1]. This close boiling point azeotrope does not separate by conventional distillation but may be competently separated by extractive distillation.

Extractive distillation is an important separation method for azeotrope mixture. In extractive distillation, an entrainer (separating agent) is used to revamp the relative volatility of component to be separated [2].

In IPA-Water mixture, ethylene glycol used as entrainer is combines with water and separated as bottom product and pure IPA is collected from the top of the column. Due to high boiling point of the solvent the ethylene glycol-water mixture may be easily separated in second distillation column. The separated ethylene glycol can be reuse as entrainer in first distillation column.

*Author for correspondence

\section{Process simulation}

\subsection{Thermodynamic model}

Thermodynamic model is used to describe phase equilibria properties of the system. For the design of chemical separation operations the phase equilibrium properties like temperature, pressure and compositions are required. In phase equilibria calculations the activity coefficients are used to calculate the component non-ideal liquid behaviour [3]. In this simulation study Non-Random Two Liquid (NRTL) model is used [4]. In this context, Figure 1 shows the xy plot and Txy plot for Isopropyl Alcohol-Water mixture.

\subsection{Residue curve analysis}

Residue Curve Analysis is useful in studying the ternary system. Residue cure enumerate the change of column composition with time in the column. Figure 2 shows the residue curve for IPA-WaterEthylene glycol, ternary system [5].

\subsection{Configuration}

The simulation of IPA-Water mixture is carried out using RADFRAC distillation model from the Aspen Plus simulator. Simulation operating conditions are specified in Table 1. Figure 3 shows the flow sheet for simulation of extractive column. Input Stream F1 and FE1 shows the feed stream of IPA-Water mixture and entrainer, respectively and output stream D1 and B1 shows the pure IPA and ethylene glycol-water mixture, respectively [6] [7]. 
Sarita Kalla et al.

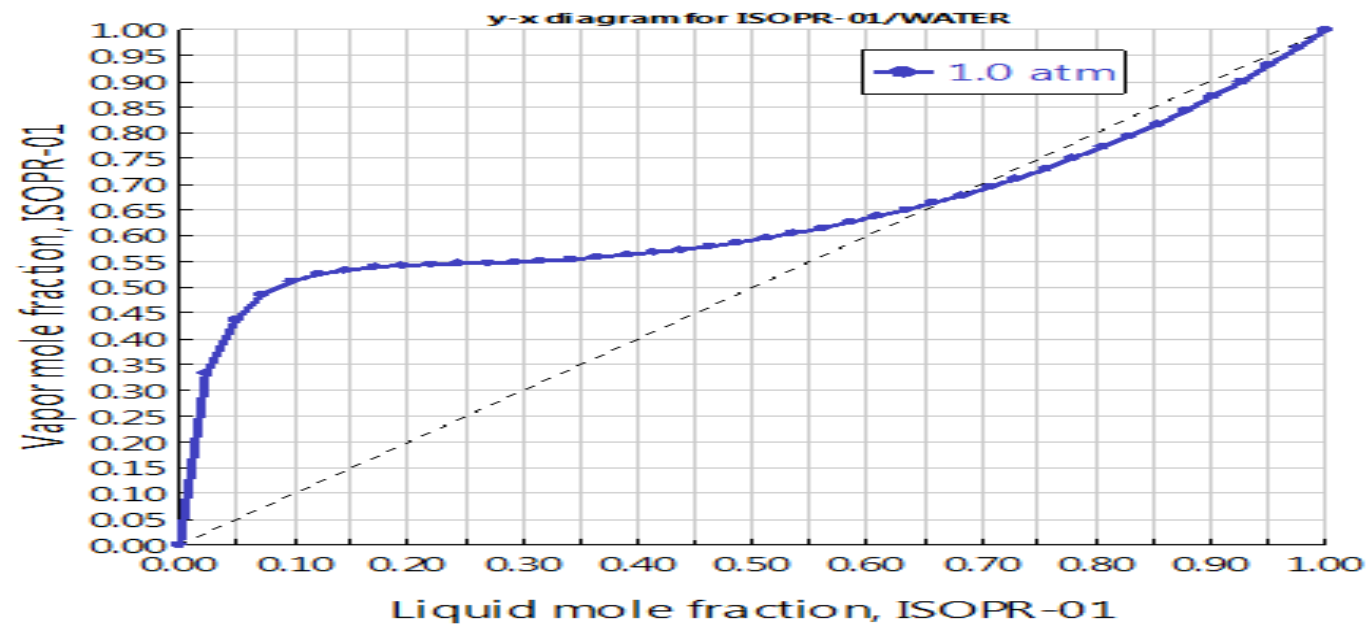

(a)

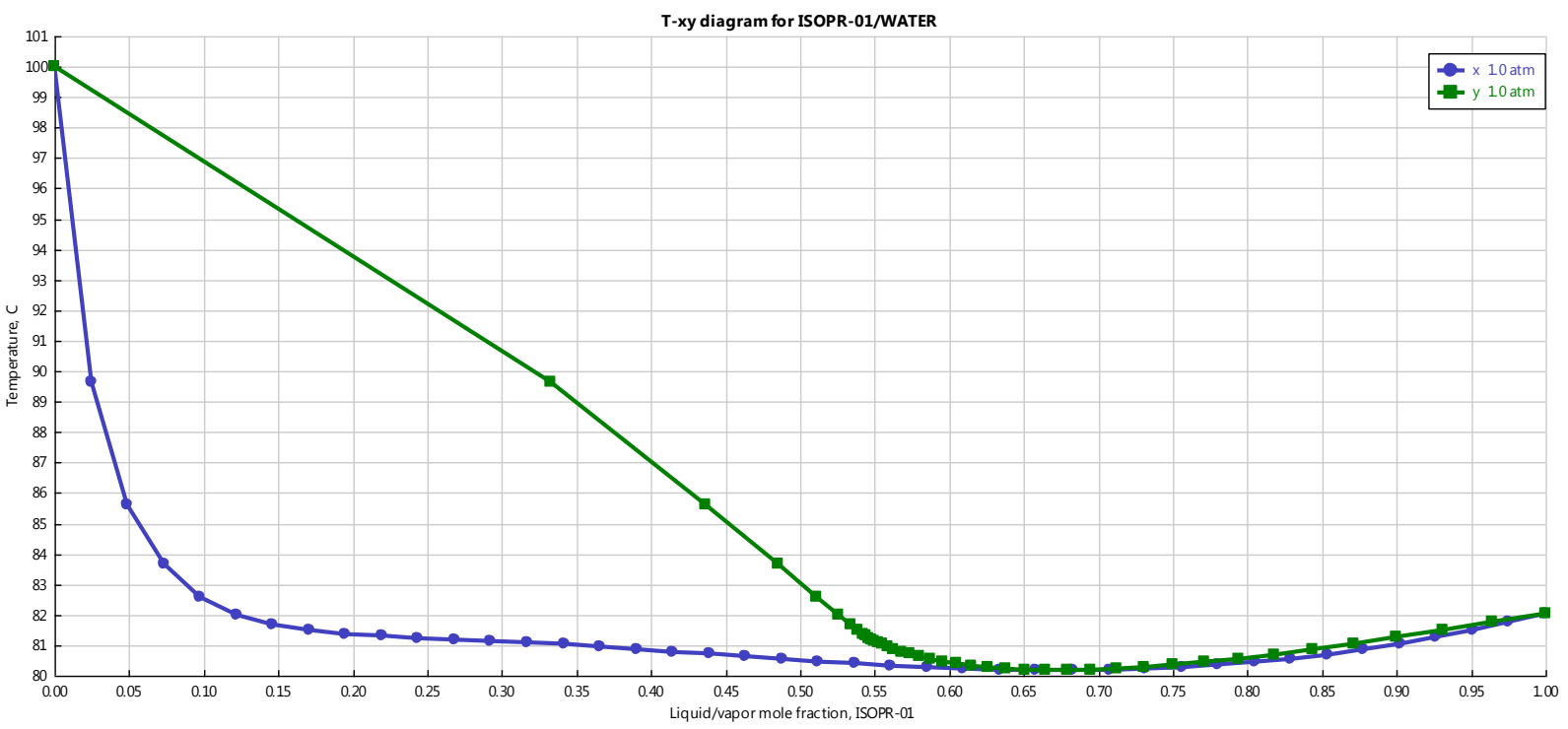

(b)

Figure 1: (a) Vapour-liquid equilibrium plot for isopropyl alcohol-water (b) txy plot for isopropyl alcohol-water

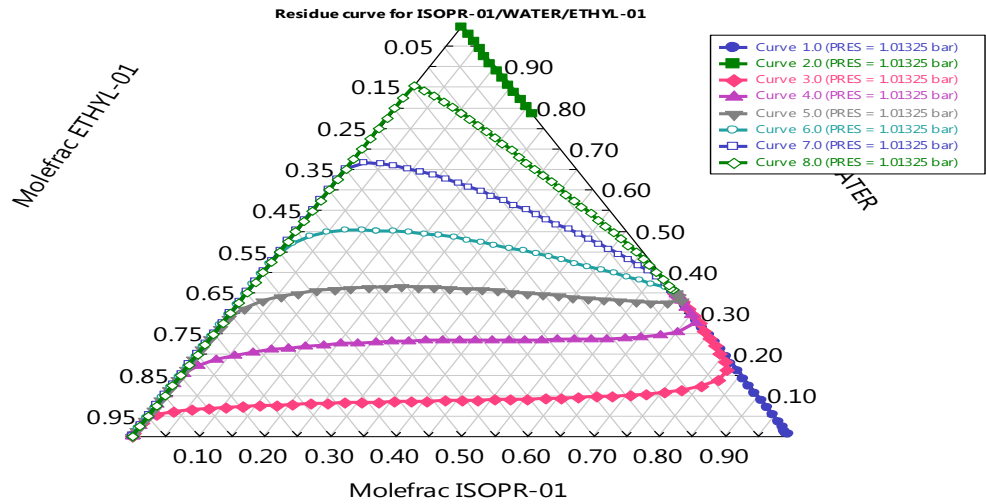

Figure 2 Residue curve for ternary system 


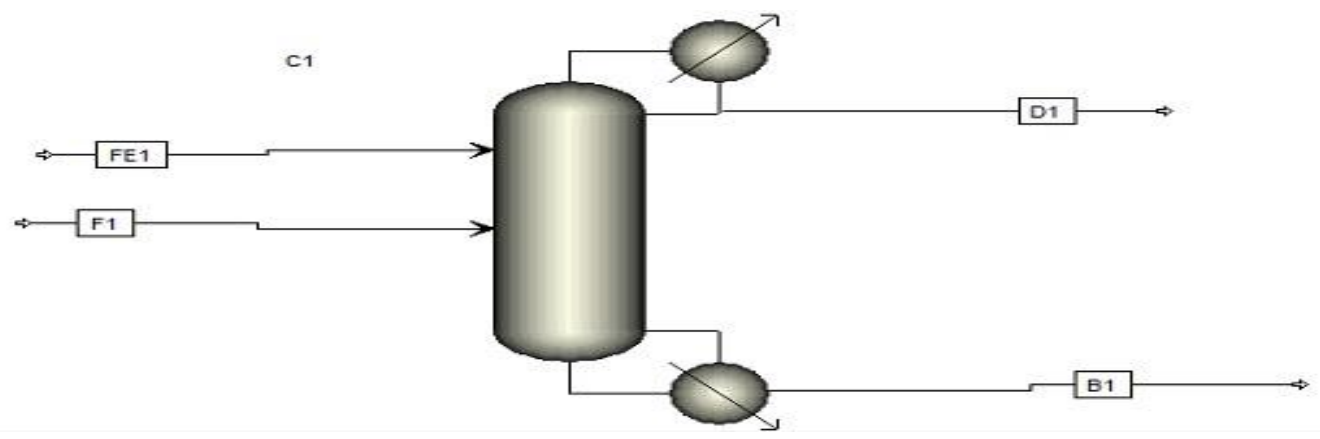

Figure 3 Flow sheet for extractive distillation

Table 1 Simulation operating conditions

\begin{tabular}{ll}
\hline Operating variable & Extractive column \\
\hline $\begin{array}{l}\text { Feed Flow Rate }(\mathrm{kmol} / \mathrm{hr}) \\
\text { Entrainer flow Rate } \\
(\mathrm{kmol} / \mathrm{hr})\end{array}$ & 100 \\
Feed Temperature $\left({ }^{0} \mathrm{C}\right)$ & 25 \\
Feed Pressure $(\mathrm{atm})$ & 1.3 \\
Entrainer Temperature $\left({ }^{0} \mathrm{C}\right)$ & 72 \\
Entrainer Pressure $(\mathrm{atm})$ & 1.1 \\
Distillate Rate $(\mathrm{kmol} / \mathrm{hr})$ & 50 \\
Molar Reflux Ratio & 1 \\
Number of theoretical & 42 \\
Stages & \\
\hline
\end{tabular}

The binary mixture of IPA-Water has the following mole fraction composition- IPA-0.5 (mole/mole), Water- 0.5 (mole/mole). Pure ethylene glycol adds as entrainer or separating agent.

\section{Results}

\subsection{Temperature profile}

From steady state temperature profile shown in Figure 4, there is no significantly change in the temperature of the column from moving down the condenser segment until it goes up to reaction temperature i.e. $385{ }^{\circ} \mathrm{C}$. From there sharply decrease in temperature up to $370{ }^{\circ} \mathrm{C}$ and finally increase in the temperature in the direction of the reboiler section.

\subsection{Composition profile}

Liquid mole fraction and Vapour mole fraction composition profile of IPA, Water and ethylene glycol is shown in the Figure 5 and Figure 6.

\subsection{Pressure profile}

From Pressure profile shown in the Figure 7, the pressure is increase with the number of stages in the distillation column.

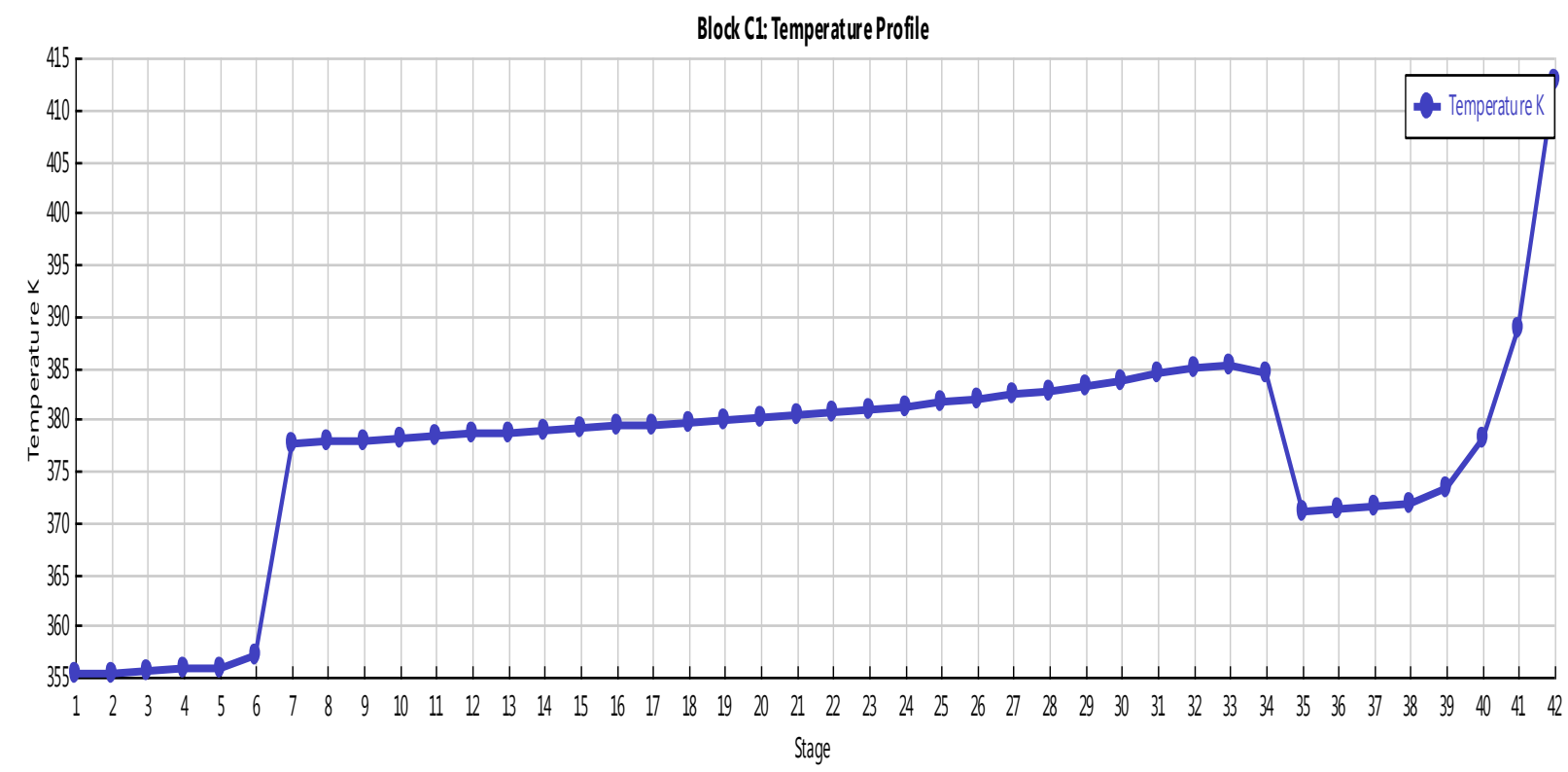

Figure 4 Temperature profile for steady state simulation (Stage wise) 
Sarita Kalla et al.

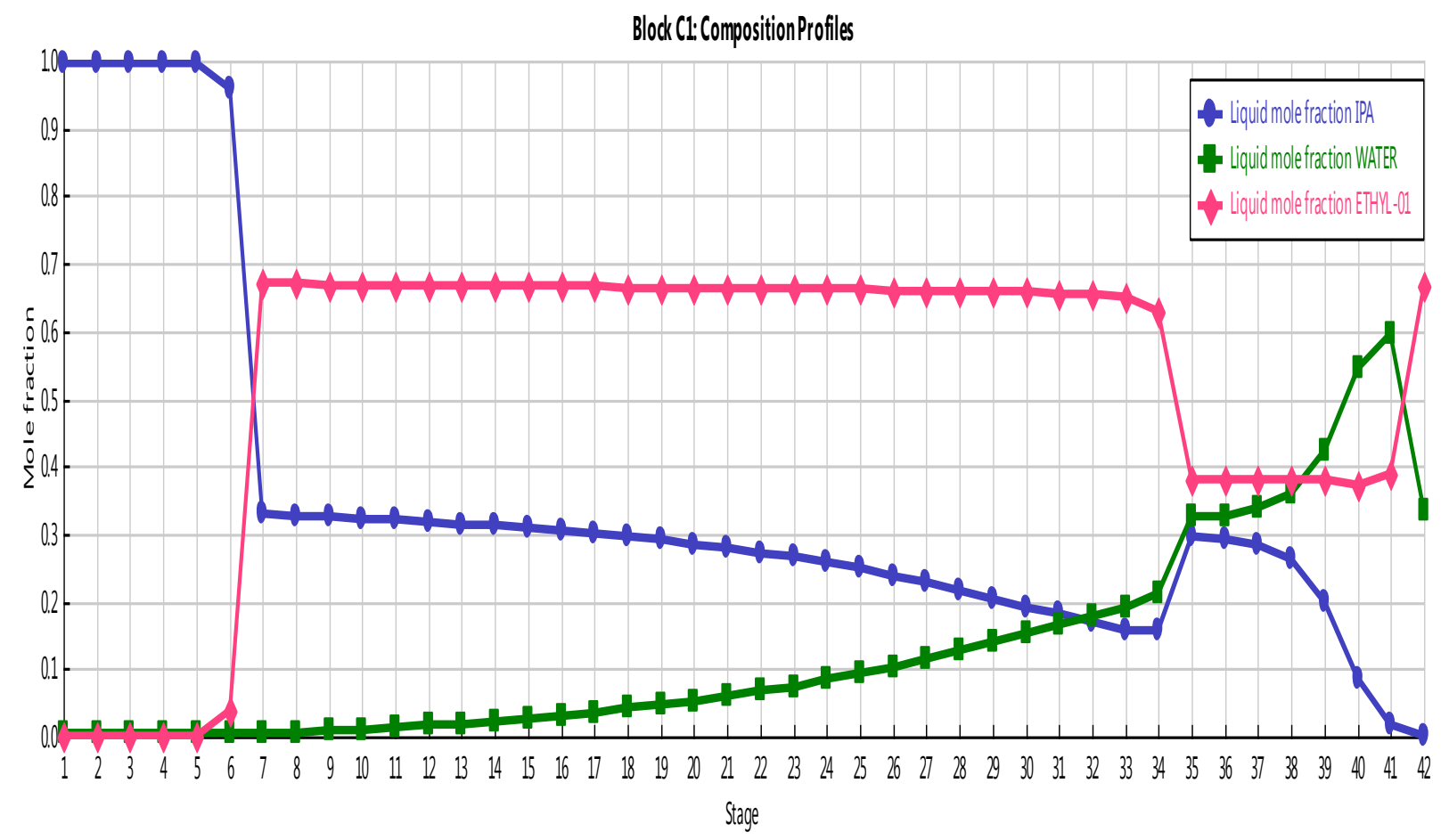

Figure 5 Liquid fraction composition profile for steady state simulation (Stage wise)

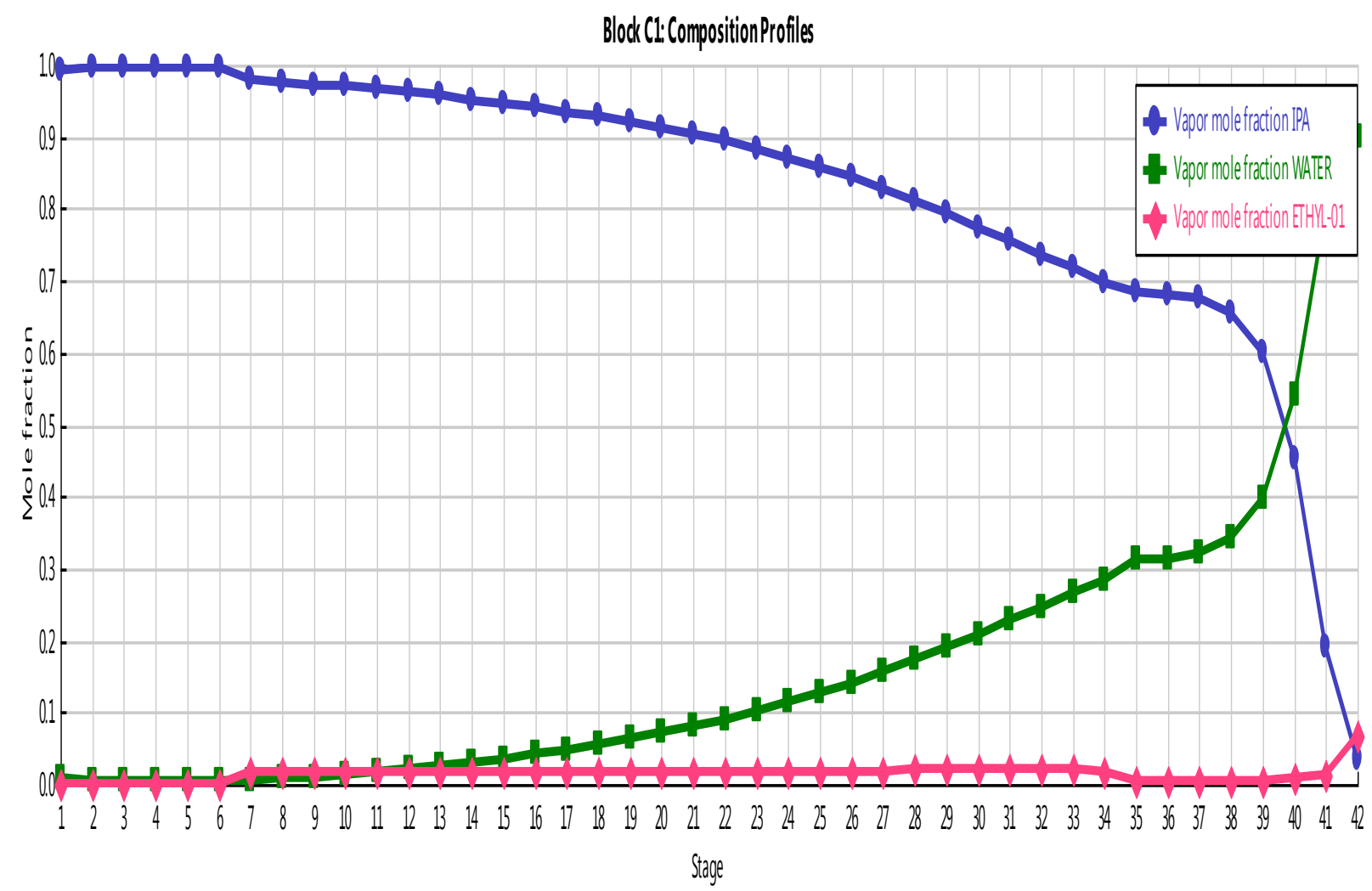

Figure 6 Vapour fraction composition profile for steady state simulation (Stage wise) 


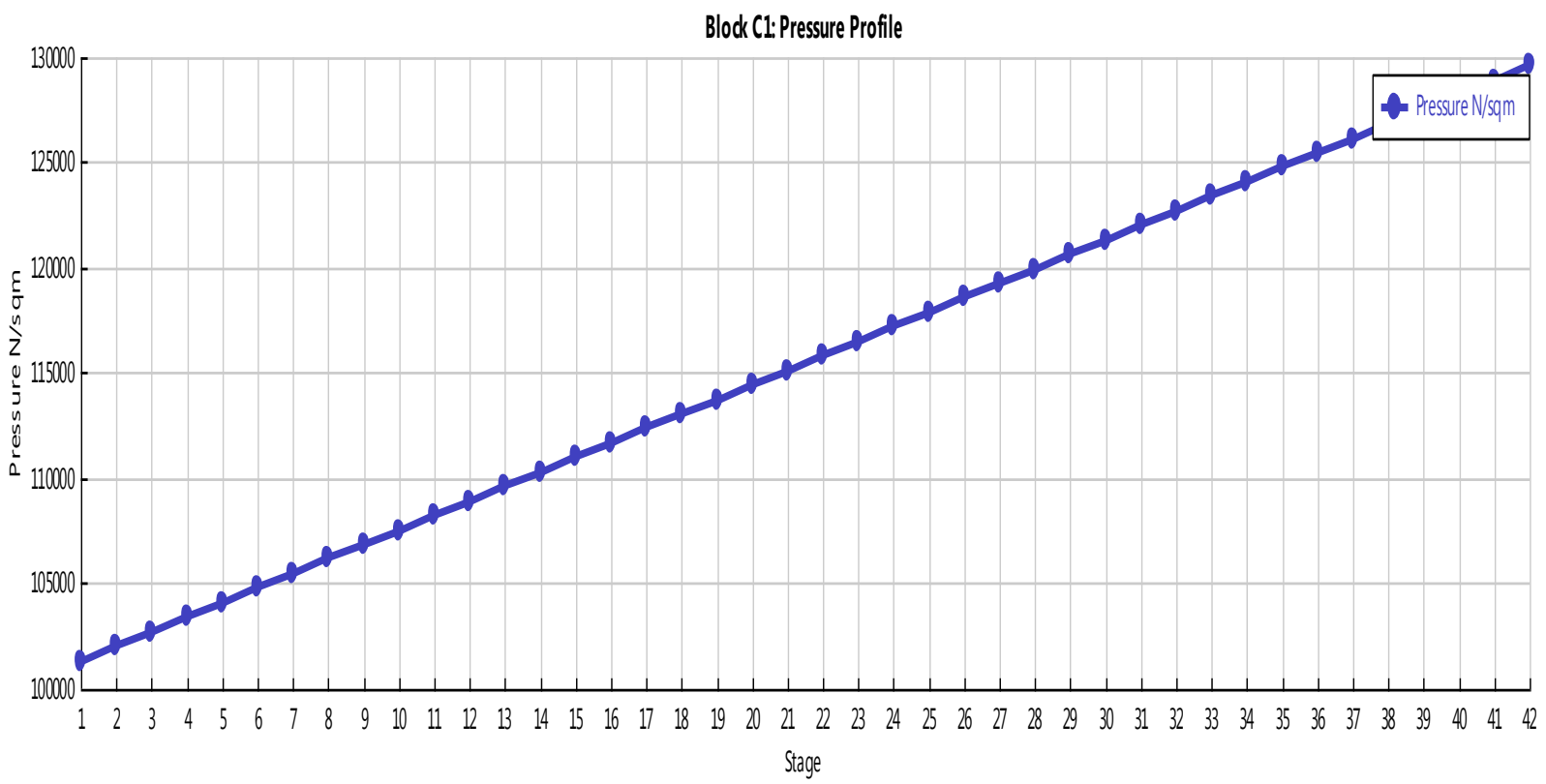

Figure 7 Pressure profile for steady state simulation (Stage wise)

\section{Sensitivity analysis}

Sensitivity analysis is a method of determining strength of relation between a given input and output [8]. In aspen plus process simulator, inputs are allowed to vary and their effects on a set of results can be calculated. Sensitivity analysis has a handful of benefits, like, studying the effect on process outputs in changing input variables, graphically shows the effects of input variables, validate that a solution to a design specification is possible or not etc. [9] [10].

\subsection{Effect of molar reflux ratio on distillate (IPA mole fraction)}

As shown in Figure 8, the distillate mole fraction is increases with reflux ratio and it becomes maximum at reflux ratio value of 1 . After this the distillate mole fraction becomes constant.

\subsection{Effect of feed flow rate (IPA-Water) on distillate}

As shown in Figure 9, as the feed flow rate increases, the distillate mole fraction increases and it becomes constant at $0.028 \mathrm{kmol} / \mathrm{sec}$.

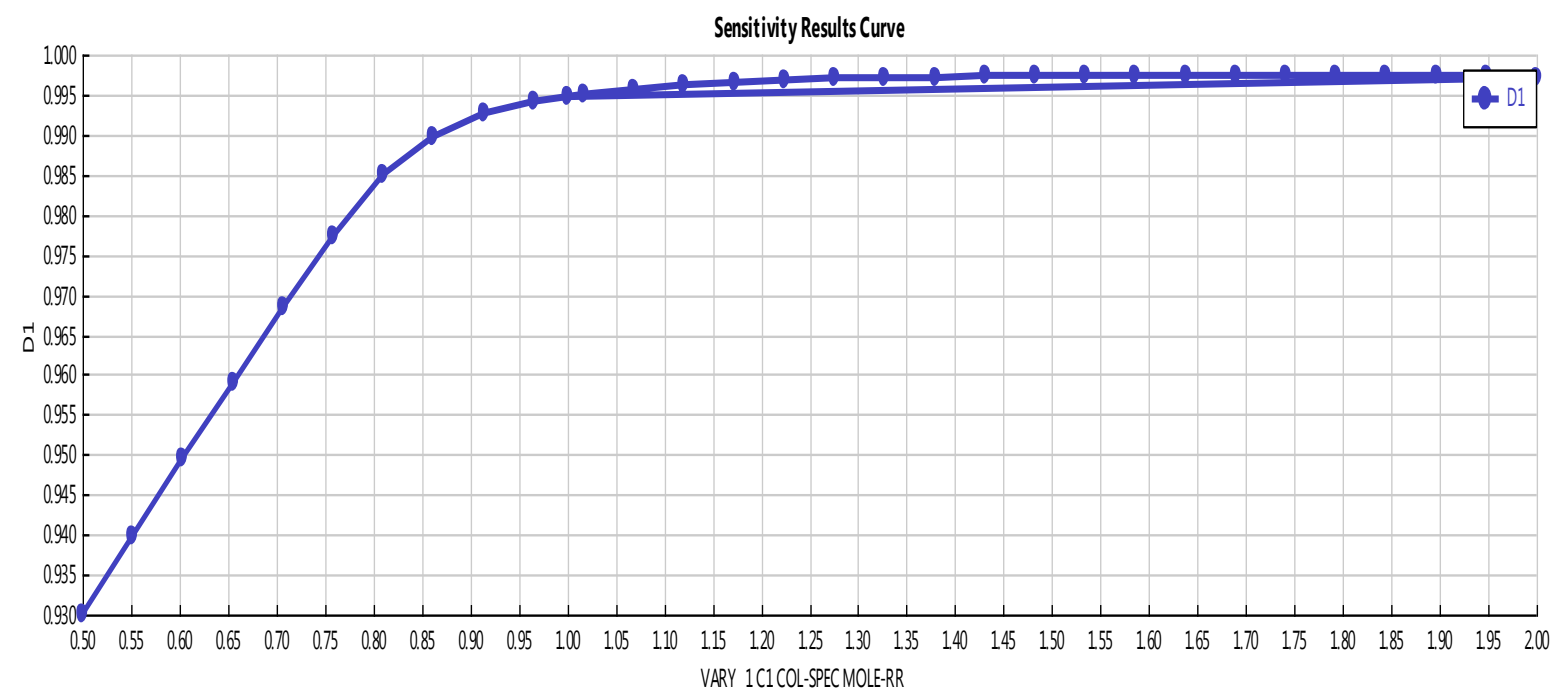

Figure 8 Result of effect of reflux ratio on IPA mole fraction by sensitivity analysis 191 


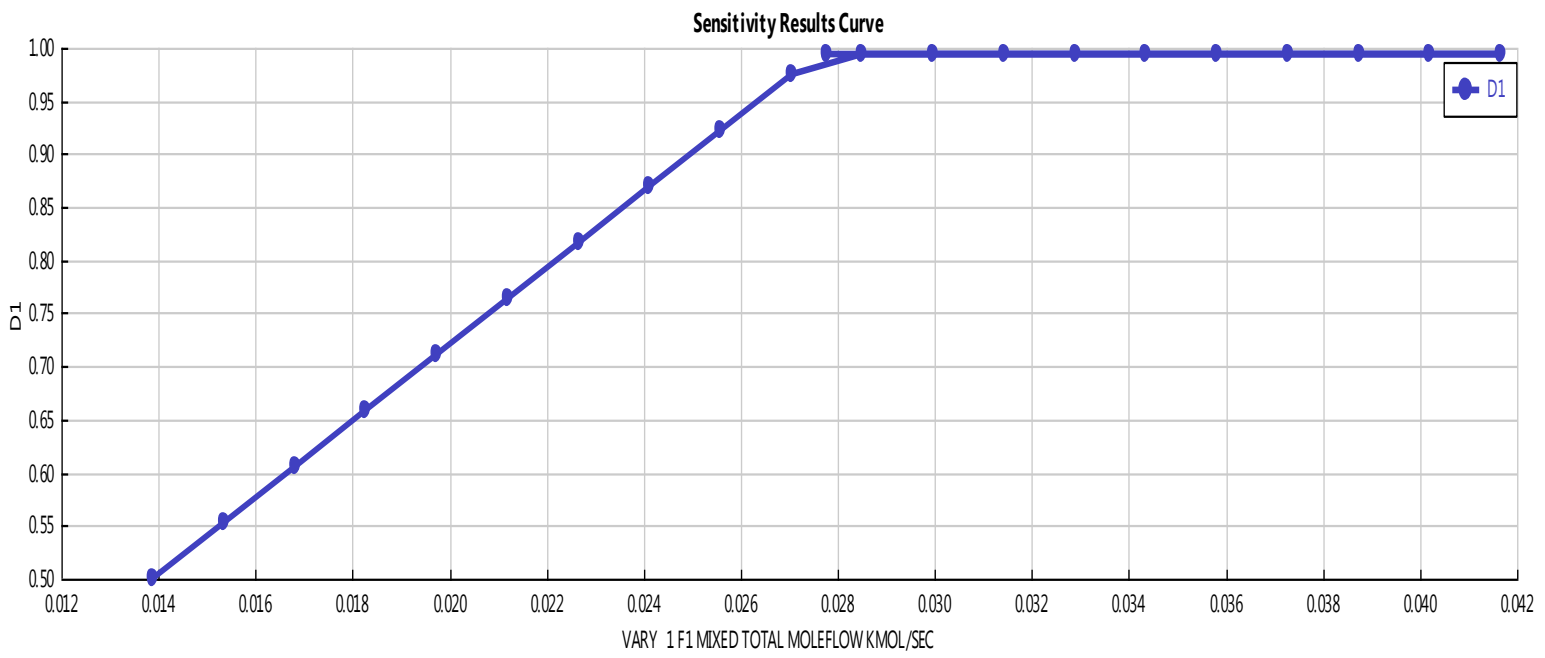

Figure 9 Result of effect of feed flow rate on IPA mole fraction by sensitivity analysis

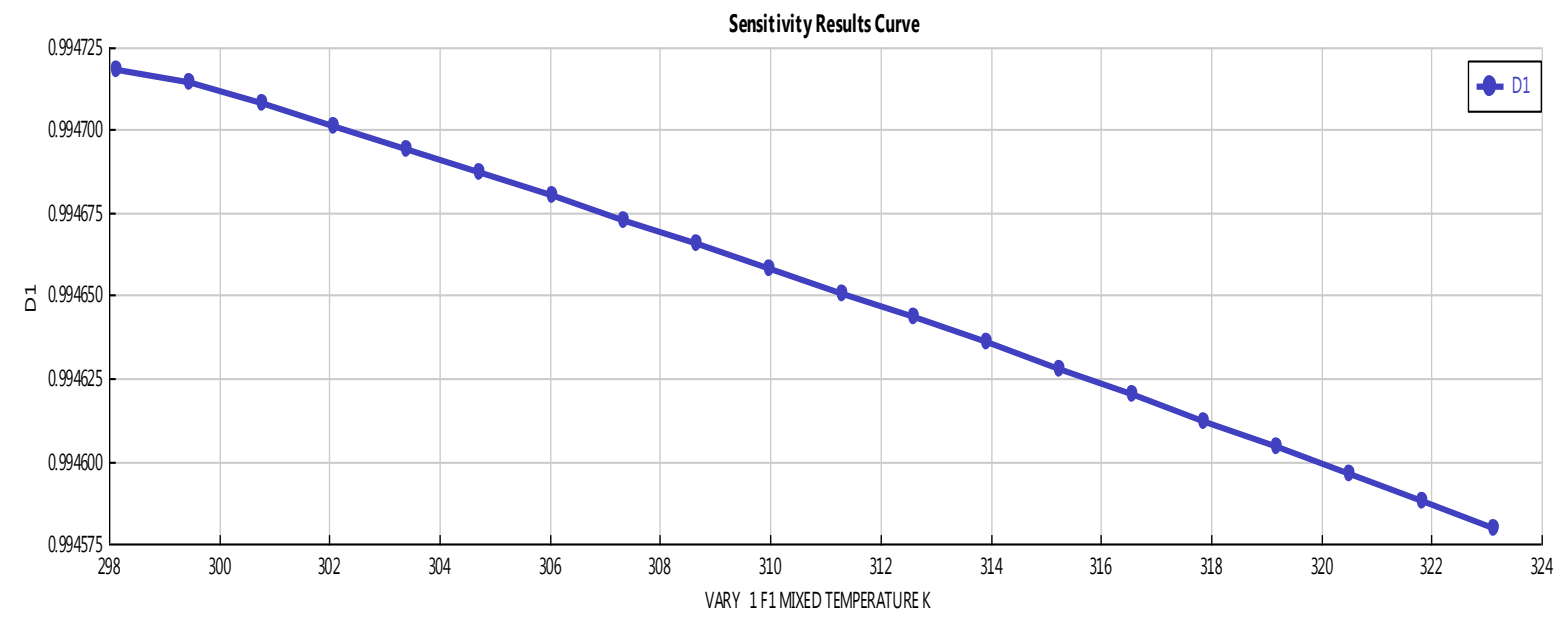

Figure 10 Result of effect of feed temperature on IPA mole fraction by sensitivity analysis

\subsection{Effect of feed temperature on distillate}

As shown in Figure 10, as the feed temperature increases, the distillate mole fraction is decreases due to exothermic nature of the reaction.

\section{Conclusion}

This work laid the foundation of operating conditions for an extractive distillation process for ethylene glycol as entrainer. At the given operating conditions, the simulation results exhibits $99.974 \mathrm{~mol} \%$ purity of IPA at the top of the column. The results of the sensitivity analysis, therefore, reveal the effect of molar reflux ratio, feed temperature and feed flow rate on the IPA purity. Isopropyl alcohol obtained in this way could be used as solvent in different applications and as cleaning agent.

\section{Acknowledgment}

None.

\section{Conflicts of interest}

The authors have no conflicts of interest to declare.

\section{References}

[1] Van Baelen G, Vreysen S, Gerbaud V, RodriguezDonis I, Geens J, Janssens B. Isopropyl alcohol recovery by heteroazeotropic batch distillation. 2010 . 979-86.

[2] Lei Z, Chen B, Ding Z. Special distillation processes. Elsevier; 2005.

[3] Gebreyohannes S, Neely BJ, Gasem KA. Oneparameter modified nonrandom two-liquid (NRTL) activity coefficient model. Fluid Phase Equilibria. 2014; 379:196-205.

[4] ASPENTECH AG. Running a process model. ASPEN Technology, Burlington. 2010. 
[5] Luyben WL. Distillation design and control using Aspen simulation. John Wiley \& Sons; 2013.

[6] Luyben WL, Chien IL. Design and control of distillation systems for separating azeotropes. John Wiley \& Sons; 2011.

[7] Brüggemann S, Marquardt W, Technische Hochschule Aachen (Germany). Lehrstuhl fuer Prozesstechnik; Shortcut design of extractive distillation columns.

[8] Saltelli A, Chan K, Scott EM, editors. Sensitivity analysis. New York: Wiley; 2000.

[9] Schefflan R. Introduction to Aspen plus, in teach yourself the basics of Aspen Plus ${ }^{\mathrm{TM}}$, John Wiley \& Sons; 2011 NJ, USA.

[10] Giwa A. Sensitivity analysis of ETBE production process using Aspen PLUS. Sensitivity analysis of ETBE production process using aspen PLUS. 2013; 3(1):293-303.

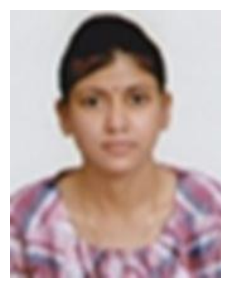

Sarita Kalla obtained her B.E. from to University of Rajasthan, Jaipur and M.Tech. from Aligarh Muslim University, Aligarh. She is presently pursuing Ph.D from Chemical Engineering Department, MNIT on Air Gap Membrane Distillation.

Email:sarita87mishra@gmail.com

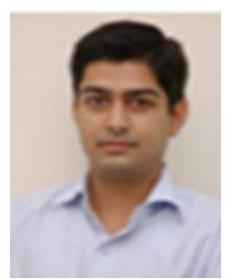

Dr. Sushant Upadhyaya obtained his Ph.D. (Chemical Engineering) from MNIT, M.Tech. and B.Tech. in Chemical Engineering from UPTU, Lucknow. He is presently Assistant Professor in Department of Chemical Engineering at MNIT. His research areas are Transport Phenomena, Modelling and Simulation, Wastewater Treatment, Computational method for linear/non-linear problems, Polymer Process Modelling, Mass Transfer, Membrane Separation Piping Engineering, Numerical Modelling, Computational Fluid Dynamics (CFD). He has published several papers of International and National repute in his research field.

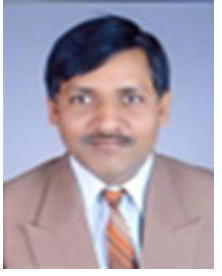

Dr. Kailash Singh received his Ph.D. from Curtin University of Technology, Australia, M.Tech. from IIT Kanpur B.E. from University of Roorkee. He is currently Associate Professor and Head in the Department of Chemical Engineering, MNIT. His research areas are Modelling and Simulation, Advanced Process Control. He has published numerous papers of International and National repute in his research field.

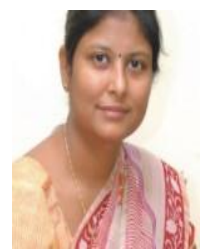

Dr. Madhu Agarwal obtained her Ph.D. from MNIT, Jaipur, M.Tech and B.Tech from Calcutta University. She is currently Assistant Professor at Department of Chemical Engineering, MNIT. Her research areas are Modelling and Simulation, Bioprocess Engineering, Biofuels, Biotechnology, Fluid Particle Mechanics, Adsorption, Wastewater Treatment. She is actively working in the area of bio fuels and water treatment. Published more than twenty papers in Journals and forty papers in conferences. She is working on two sponsored research projects on Fluoride removal and fluoride detection. Guiding B.Tech. \& M.Tech. Students for their final year projects and Dissertation work and her four Ph.D. Students are working on alternative energy and water treatment.

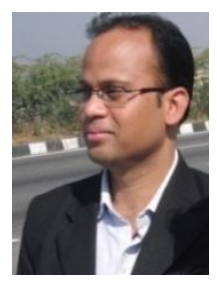

Rajeev Kumar Dohare received his Ph.D from MNIT, Jaipur, B.E from NIT, Surat in 2002 and M.Tech from Aligarh Muslim University, Aligarh, India in 2006 with first class. Now he is working as Assistant Professor in the Department of Chemical Engineering at Malaviya National Institute of Technology Jaipur. His Research areas are process modelling, simulation and control, solid waste management, fluid mechanics, and processes optimization. He has published several papers of International and National repute in his research field. 